\title{
Spatially resolved transcriptomics reveals plant host responses to pathogens
}

\author{
Michael Giolai ${ }^{1,2}$, Walter Verweij ${ }^{2,3}$, Ashleigh Lister ${ }^{2}$, Darren Heavens ${ }^{2}$, lain Macaulay ${ }^{2}$ and Matthew D. Clark ${ }^{2,4^{*}}$ (1)
}

\begin{abstract}
Background: Thorough understanding of complex model systems requires the characterisation of processes in different cell types of an organism. This can be achieved with high-throughput spatial transcriptomics at a large scale. However, for plant model systems this is still challenging as suitable transcriptomics methods are sparsely available.

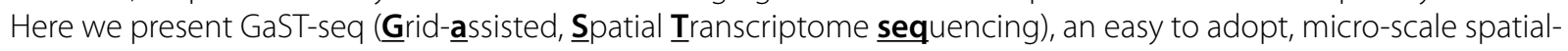
transcriptomics workflow that allows to study expression profiles across small areas of plant tissue at a fraction of the cost of existing sequencing-based methods.
\end{abstract}

Results: We compare the GaST-seq method with widely used library preparation methods (Illumina TruSeq). In spatial experiments we show that the GaST-seq method is sensitive enough to identify expression differences across a plant organ. We further assess the spatial transcriptome response of Arabidopsis thaliana leaves exposed to the bacterial molecule flagellin-22, and show that with eukaryotic (Albugo laibachii) infection both host and pathogen spatial transcriptomes are obtained.

Conclusion: We show that our method can be used to identify known, rapidly flagellin-22 elicited genes, plant immune response pathways to bacterial attack and spatial expression patterns of genes associated with these pathways.

Keywords: Spatial transcriptomics, Transcriptomics, Transcriptome landscape, RNA-seq, Plant immunity, Plant defence response, flg22, Oomycete, PAMP, FLARE, Biotic interaction, GaST-seq

\section{Background}

Most model plants and all crops species are multicellular, consisting of multiple organs and cell types with a multitude of physiological states [1]. A thorough understanding of these complex systems requires the ability to dissect and characterise processes in the different organs and cell types. This is challenging, though recently multiomics single-cell studies have been flourishing [2], but high-throughput, high-resolution methodologies that assess molecular conditions with spatial resolution are sparsely available [3-6].

Although some spatial and low-input transcriptome profiling methods have been developed for animal model organisms [3-5, 7], these methods are difficult

\footnotetext{
*Correspondence: matt.clark@nhm.ac.uk

${ }^{4}$ Natural History Museum, London, UK

Full list of author information is available at the end of the article
}

to transfer to plants $[6,8]$. In comparison to animal cells, plant tissues hold a series of additional challenges: the robust plant cell wall requires specialised sample preparation (which makes reproducible, high-throughput sample preparation more difficult) and some plant secondary metabolites e.g. polyphenols can inhibit downstream enzymatic processes [9]. For plants, single plant cells (protoplasts) can be obtained by enzymatic removal of plant-cell walls and subsequent fluorescent activated cell sorting (FACS) assays [10]. At the sub-cellular scale plant nuclei can be isolated within minutes by cell lysis and FACS [10-12]. However, 'stimulus and response' assays, such as differential gene-expression experiments or the characterisation of cell-type transcripts could be affected by these additional experimental procedures before RNA-extraction. Another important factor is the loss of spatial information when nuclei or protoplasts are extracted from a tissue. 
Thus methods such as fluorescent in-situ hybridisation (FISH) [13], laser-capture microdissection (LCM) [14-16] or the SPATiAL TRANSCRIPTOMICS [4, 6] workflow are better suited to understand spatial transcription changes. However, all three methods need specific tissue preparations (e.g. cryo-sectioning, permeabilization or fixation) and specialised protocols to assess transcriptome levels: FISH methods require imaging of transcripts and are restricted to multiplexing a few fluorescent anti-sense probes at a time [3], LCM requires specialised equipment and training for precise, laborious excision of specific tissue elements [6] and the SPATiAL TRANSCRIPTOMICS protocol requires preparation of thinly sectioned, permeabilised samples and custom made DNA arrays $[4,6]$.

Despite the high level of resolution that can be achieved with all these methods, they are not easily applied in most laboratories. We aimed to overcome this with our GaST-seq workflow. GaST-seq is designed to quickly process mechanically dissected samples into sequencing libraries using standard laboratory equipment and can be used in most modern laboratories. GaST-seq is based on three consecutive steps: (1) rapid, mechanical sample dissection of small e.g. $1 \mathrm{~mm}^{2}$ leaf areas (2) a high-throughput method for high quality mRNA extraction of difficult to lyse plant tissues and (3) next generation sequencing (NGS) library construction and sequencing (Fig. 1).

In a series of experiments, we compare the performance of GaST-seq with standard RNA-seq (Illumina TruSeq) experiments. Using Illumina sequencing we identify differentially expressed (DE) genes in 1D (across lateral leaf sections) observing how transcripts and expression levels vary across the tissues that make up the leaf organ. We compare large-scale vs. fine-scale transcriptome experiments ability to detect plant responses induced by the bacterial peptide flagellin-22 (flg22), a well-described pathogen-associated molecular pattern (PAMP) that triggers plant immune responses [17]. By comparing our data with published datasets for 'flagellin rapidly elicited' (FLARE) genes [18] we identified 143 of 253 described FLARE genes that overlap with our data, and a further 428 genes with similar expression patterns to FLARE genes. We show that the detected 428 transcripts, are enriched for plant defence responses and that spatial transcriptome data can be used to reconstruct the spatial expression of pathway components across leaves. In additional pilot experiments using Arabidopsis thaliana and the oomycete pathogen Albugo laibachii we also show that the dual dataset of both host and pathogen, are captured, and spatial expression profiles can be constructed which could be used to study the biotic interactions in infections.

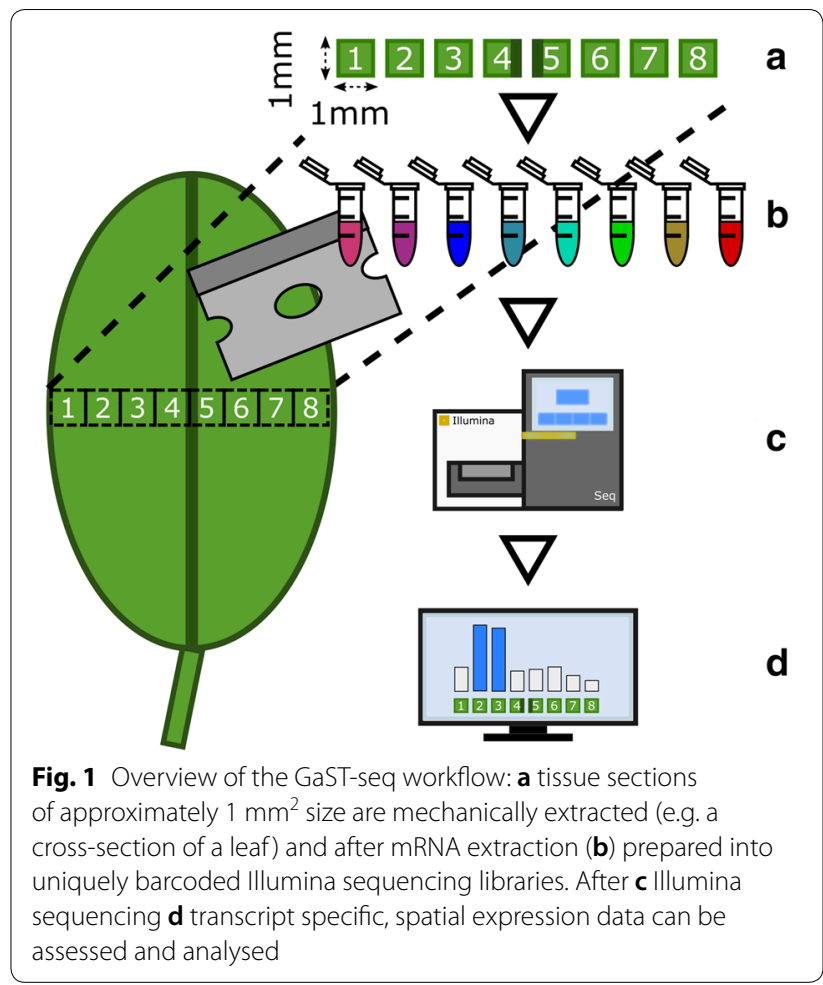

\section{Results}

Does leaf dissection induce wounding response gene expression profiles?

Physical wounding of plants is known to induce wounding related gene expression [19]. This is an important point to consider as the GaST-seq workflow dissects tissue into $\sim 1 \mathrm{~mm}^{2}$ squares followed by immediate snap freezing on dry ice. Yet dissection could potentially lead to activation of wounding related gene expression and dissection takes longer as the resolution increases (grid size). As any wounding effect could form a technical limitation to GaST-seq we measured the number of DEgenes found after tissue dissection. For this we prepared $\sim 1 \mathrm{~mm}^{2}$ leaf squares (3 biological replicates per timepoint) at the time-points: $0-\mathrm{min}, 2.5-\mathrm{min}, 5-\mathrm{min}$ and 10 -min between cutting and freezing on dry ice (when all enzymatic reactions cease). To determine the number of DE-genes at each time-point we compared the $2.5-\mathrm{min}$, 5-min and 10-min samples with the 0-min samples as an unwounded reference. This analysis showed just $1 \mathrm{DE}$ gene (AT2G37130) at the 2.5-min time-point (which was not significant at later time-points) there were no DEgenes at the 5-min time-point and 13 genes at the 10-min time-point (see: Additional files 1 and 2) suggesting that the transcriptional response to wounding starts between 5 and $10 \mathrm{~min}$. We looked for enriched biological processes in the combined set of 14 genes and detected three 
genes at the 10-min time-point being associated with the GO-term 'response to wounding': TPSO4, TAT3 and AT1G62660 (see: Additional files 1 and 2). This indicates that it is highly desirable to cut and snap freeze sample material within $10 \mathrm{~min}$ to avoid perturbation of resultsa time window in which we find that sample dissection is easily achievable.

\section{Spatially resolved transcriptomics data reveals leaf tissue specific gene expression}

We assayed GaST-seq's ability to detect known gene expression differences between tissue types in untreated leaves. Briefly, we dissected a lateral cross-section of an A. thaliana leaf (3 biological replicates) into a 1-dimensional (1D) expression map of eight circa $1 \mathrm{~mm}^{2}$ squares (Fig. 2a). Each cross-section was sampled according to the same pattern: the leaf margins were located at square-1 and square- 8 and the midvein at square- 5 . We then identified DE-genes by comparing the midvein with the lamina and the leaf margins with the lamina. This resulted in $393 \mathrm{DE}$-genes for the midvein and $686 \mathrm{DE}$-genes for the leaf margins comparison (Fig. 2 and Additional file 2).

\section{Comparison of spatial and bulk transcriptomics after localised flg22 stimulation}

To compare spatial (only treated areas) with bulk (large leaf areas with treated and untreated areas) PAMP immune responses we used a flg-22 syringe infiltration assay. For this we produced small, local infiltration spots on the abaxial, left-hand side of a leaf of 6 biological $A$. thaliana replicates using either $500 \mathrm{nM}$ flg22 or water (Fig. 3a). We incubated the plants for $1 \mathrm{~h}$ and sampled by dissecting leaf samples with a 1D system as above, briefly: square-1 (in the middle of the left half of a leaf) as infiltration spot and then laterally towards the midvein square- 2 as non-vascular leaf tissue, square- 3 as the midvein and square- 4 as non-vascular leaf tissue.

In our analysis we wanted to measure how bulk RNAseq datasets compared to spatially collected ones by using the number of detectable DE-genes. We hypothesised that the spatial analysis of the small, local treatment spot (square-1) and its surroundings (square-2, square- 3 and square-4) would reveal more and distinct types (or waves) of flg22 responsive DE-genes than a bulk analysis would-especially of rarer transcripts. To measure the effect of spatial information alone we simulated an in silico flg22 bulk experiment by combining the data from flg22 or water treated square- 1 with the other untreated squares-2, 3 and 4 of the same leaf. We then called the treatment responsive DE-genes from the bulk files, detecting 65 DE-genes (39 higher expressed, 26 lower expressed) $1 \mathrm{~h}$ after flg22 infiltration. We detected 887 more DE-genes (952 in total) by comparing the single squares of the flg22 and water infiltration
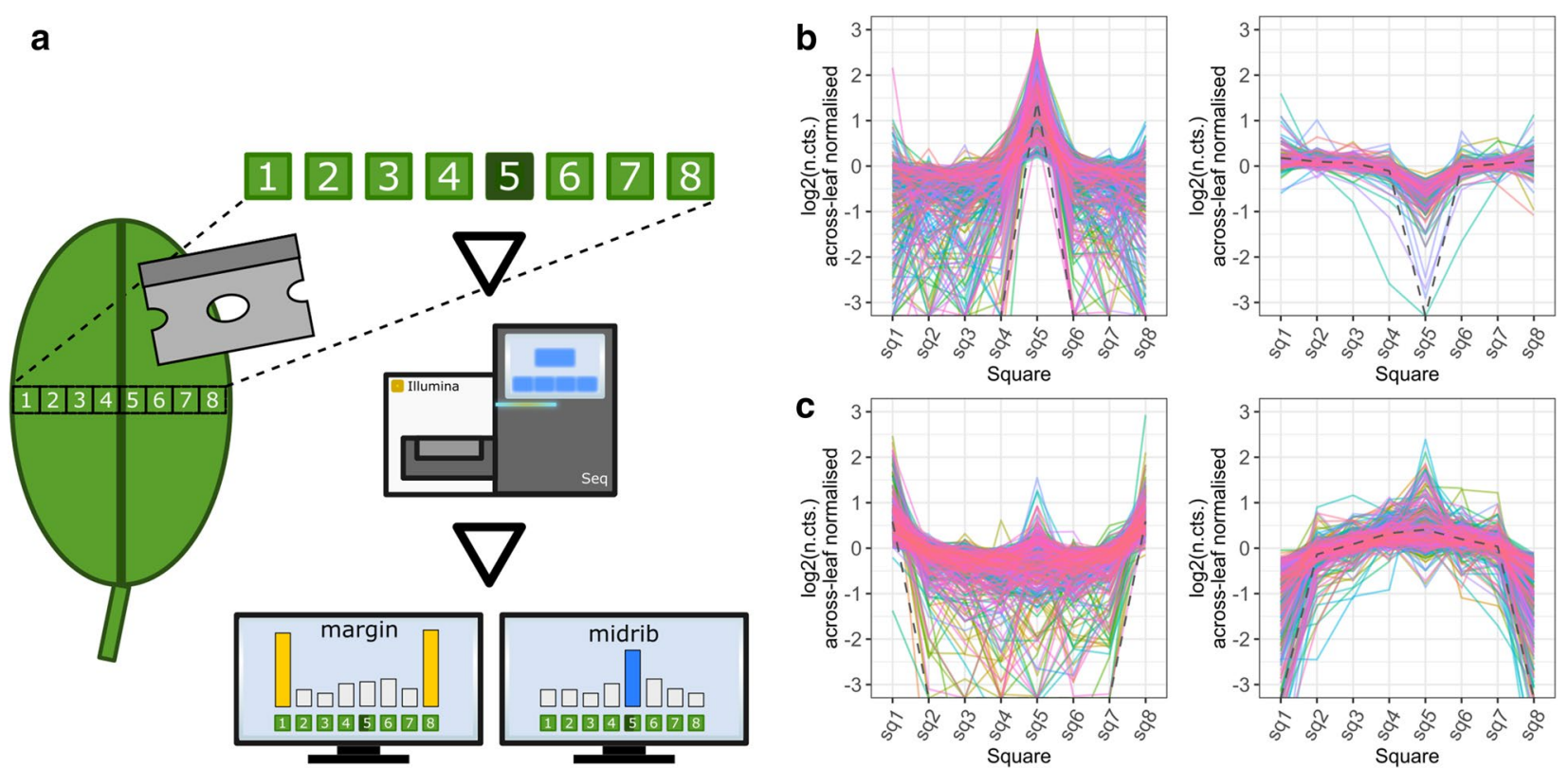

Fig. 2 Identification of midvein and edge DE-genes in a lateral 1D leaf cross-section: a DE-gene analysis of a 1D A. thaliana leaf lateral cross sections by comparing the midvein (square-5) or the margin squares (square-1 and square-8) with the 'bulk' (remaining) leaf sections. The two images in b show 393 DE-genes with higher (left, 256 DE genes) or lower (right, 137 DE genes) expression values in the midvein. The images in c show 686 DE-genes higher (left, 403 DE genes) or lower (right, 283 DE genes) expression in the leaf margins. The grey dashed line in each plot (b and $\mathbf{c}$ ) represents a trend-line for the average $\log _{2}$ (normalised counts) of all genes normalised across the leaf squares 


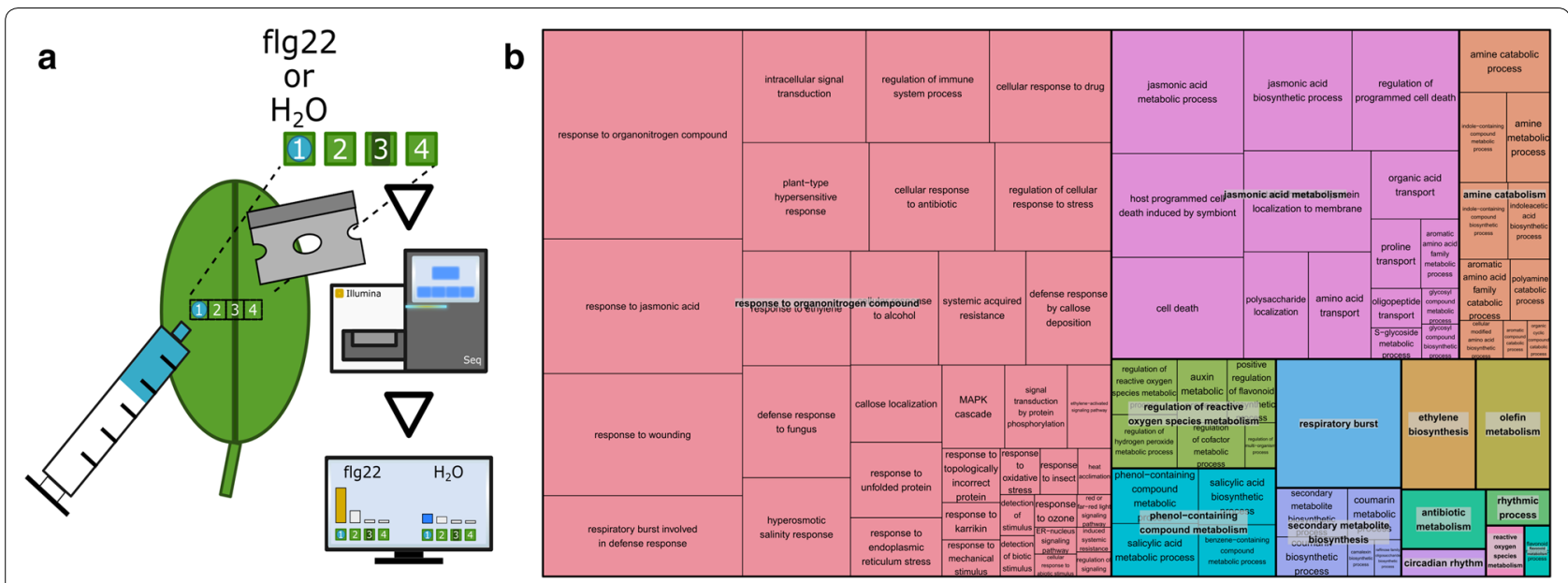

Fig. 3 Elicitation of early A. thaliana defence response genes by infiltrating the bacterial peptide flg22: a To provide a strong stress stimulus we used syringe infiltration of either $500 \mathrm{nM}$ flg22 or, as a control, water on a small area of the abaxial side of a leaf (square-1). $1 \mathrm{~h}$ after infiltration we dissected 4 squares of a lateral leaf section with square- 1 being the infiltration spot, square- 2 and square- 4 untreated, non-vascular leaf tissue and square-3 as midvein. The figure in $\mathbf{b}$ shows the REVIGO [20] treemap of the detected 168 GO-terms grouped under parent terms such as 'response to organonitrogen compound' (rose), 'jasmonic acid metabolism' (purple), 'amine catabolism' (orange) 'regulation of reactive oxygen species metabolism' (green), 'phenol-containing compound metabolism' (azure blue), 'respiratory burst' (blue), etc.. The size of each rectangle relates to the absolute $\log _{10}$ (q-value) - the larger the more significant

dataset: 646 DE-genes for square-1 (416 higher, 230 lower expressed), $401 \mathrm{DE}$-genes for square-2 (306 higher, 95 lower expressed), 9 DE-genes for square-3 (8 higher, 1 lower expressed) and any DE-genes for square-4 (see: Additional file 2). In contrast comparing the gene lists of the in silico bulk and spatial analysis we detected that 4 DE-genes were exclusively called from the bulk dataset and 64 genes were shared by both datasets.

To identify the biological processes uncovered by our transcriptomics experiments we performed a GOterm enrichment analysis the spatial flg22 related DEgene datasets. From all (952) DE-genes we obtained 168 enriched GO-terms; among them we observed a high number of biological processes related to stress and defence responses (see: Fig. 3b).

\section{Early elicited flg22 response genes of local, fine-scale stimulation}

To simulate an initial pathogen encounter we used a milder stimulus method than the above described syringe infiltration: we prepared 6 biological $A$. thaliana replicates by depositing $1 \mu \mathrm{l}$ of $500 \mathrm{nM}$ flg22 on square- 3 of the abaxial side of a leaf and $1 \mu \mathrm{l}$ of water (internal control) on square-6 (equivalent locations due to leaf bilateral symmetry). After $1 \mathrm{~h}$ we extracted the treated leaf area as a $1 \mathrm{D}$ lateral cross-section containing 8 separate $1 \mathrm{~mm}^{2}$ squares (Fig. 4a). We were interested in DE-genes at the site of flg22 spotting (square-3) and in adjacent sections (square-2 and square-4) as we reasoned that the plant would respond to the PAMP locally at first and then responses via signalling to adjacent tissues and the rest of the plant. We called DE-genes by comparing the flg22 with the water droplet spots (square-3 vs square-6) and the adjacent sections with their corresponding bilateral equivalents (square- 2 vs square- 7 and square- 4 vs square-5). Due to the milder stimulus in comparison to the flg22 infiltration dataset we expected the number of DE-genes could be lower than in the syringe infiltration experiment where we detected $952 \mathrm{DE}$ genes. Indeed, we identified a lower number of $523 \mathrm{DE}$-genes (491 higher expressed, 32 lower expressed) for the droplet spot, and $5 \mathrm{DE}$-genes in the adjacent sections (1 higher expressed DE-gene in the square-4 square-5 comparison and 4 higher expressed DE-genes in the square- 2 vs square 7 comparison). Thus, in total we detected 526 individual DE-genes.

We compared both droplet spotting and syringe infiltration datasets (each dataset was collected $1 \mathrm{~h}$ after flg22 exposure) for biological processes using GO-term enrichment. Both experiments produced a similar number of enriched GO-terms with 159 biological processes enriched in the droplet spotting dataset and 168 biological processes enriched in the infiltration dataset, with an overlap of 132 biological processes (83.0\% of the spotting dataset and $78.5 \%$ of the infiltration dataset) between both datasets (see: Additional file 2). The percentage of shared, enriched GO-terms indicated the presence of a similar plant response to flg22 in both experiments despite the difference in quantity of stimulant. 


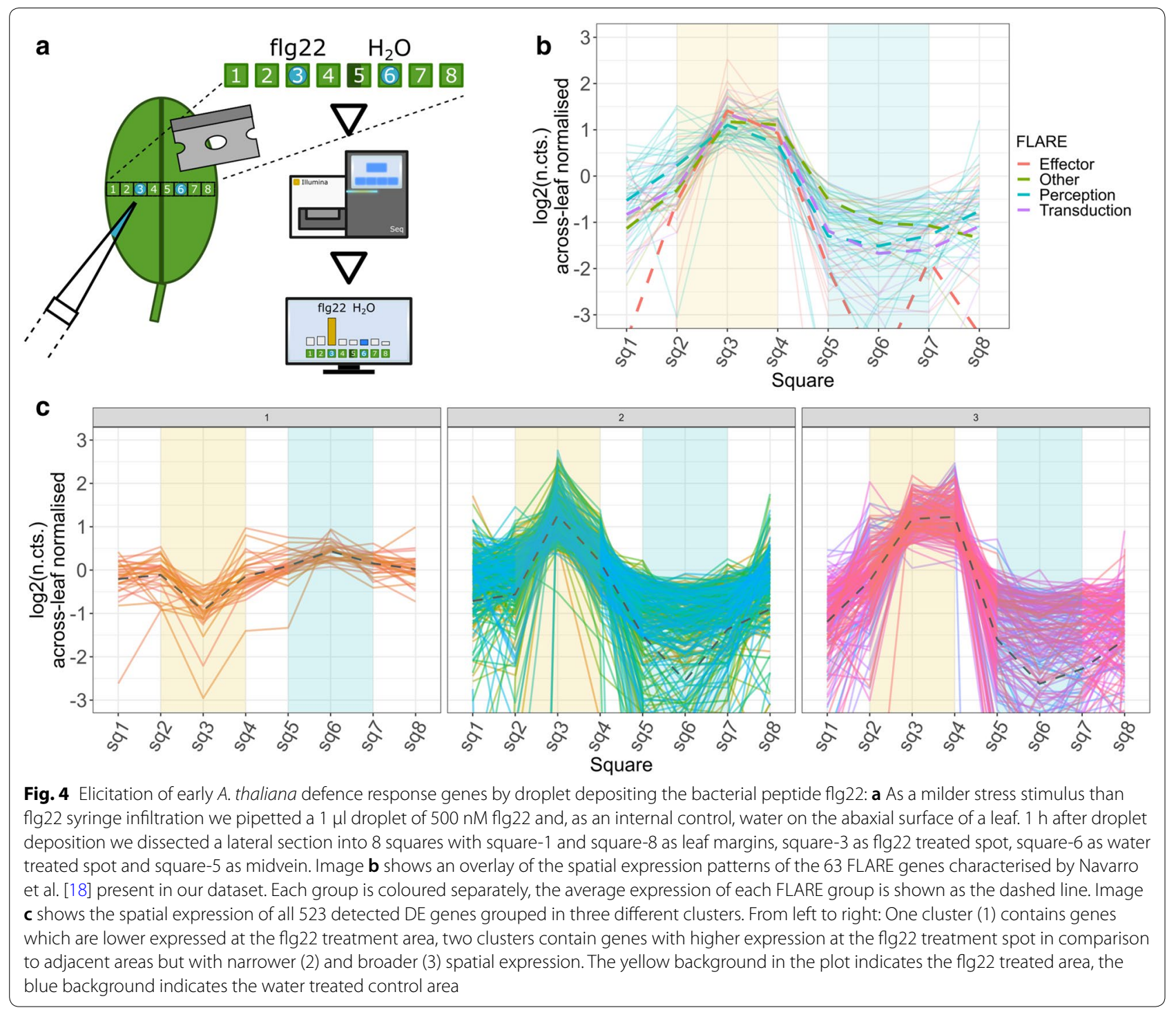

We measured the DE-genes with the 253 flagellin rapidly elicited (FLARE) genes described by seedling and cell culture flg22 exposure experiment of Navarro et al. [18] (see: Additional file 2). We found that the DE-genes of the droplet spotting experiment contained 25\% FLARE genes (63 of 253 genes). These consisted of 32 FLARE genes associated with signal transduction, 11 genes associated with roles in signal perception, 14 with known or putative roles as effector proteins and 9 FLARE genes identified by Navarro et al. as 'other' FLAREs (see: Additional file 2). We found a slightly higher number in the infiltration experiment: $80 \mathrm{DE}$ genes were shared with the 253 FLARE genes (32\%) with 39 genes associated with signal transduction, 16 genes in signal perception, 15 genes with known or putative roles as effector proteins and 11 genes with other functions (see: Additional file 2). Interestingly the \% of known FLARE and the number of enriched biological processes was higher in the infiltration than the spotting experiment (possibly suggesting other processes are triggered by infiltration).

We were interested in the spatial expression patterns of the 63 shared FLARE genes between our droplet spotting experiment and the Navarro et al. dataset. For this we visualised the expression patterns of the FLAREs across the studied leaf area. All 63 FLARE genes showed high expression levels at the area of flg22 exposure in comparison to adjacent leaf squares (Fig. 5b). To study the expression profiles of the remaining $460 \mathrm{DE}$ genes identified in the flg22 droplet spotting experiment, we affinity propagation clustered [21] these DE genes based on their spatial expression patterns and visualised the expression profile of each cluster (Fig. 4c). We identified three gene clusters: two of the three clusters contained genes with higher expression levels at or adjacent to the area of flg22 

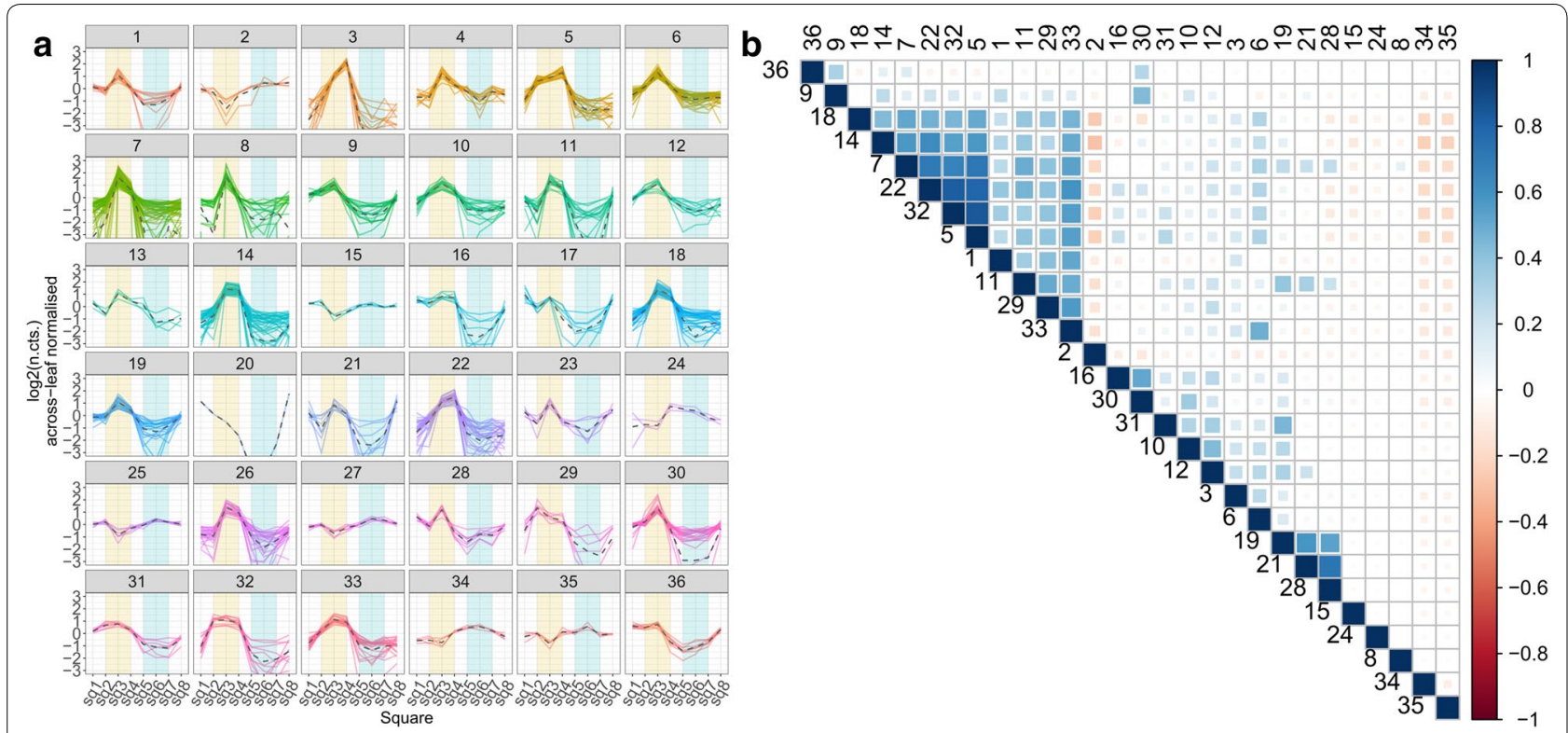

Fig. 5 Unsupervised clustering of flg22 elicited DE genes and GO-term correlation matrix of the predicted clusters: a the expression profiles of the 523 flg22 elicited DE genes grouped to 36 clusters precisely clustered according to their spatial expression pattern across the tested leaf area. Many of the clusters show differences in their induction profile at the site of flg22 deposition (yellow background) but also differences in expression at the water treated area (blue background) or the expression at the leaf boarders. $\mathbf{b}$ The correlation analysis of the enriched GO-terms from the genes of the spatial clusters shown in $\mathbf{a}-28$ clusters grouped with hierarchical clustering for enriched GO-terms

treatment and one cluster contained a group of lower expressed genes at the flg22 treated area (Fig. 4c).

We analysed all clusters for enriched biological processes using GO-term analysis. We could not detect any enrichment in biological processes for the cluster containing the DE genes which were lower expressed at the flg22 site. The two clusters with expression peaks at the site of flg22 stimulation however enriched 135 and 122 biological processes. Of all biological processes 100 were shared between both clusters and 35 as well as 22 biological processes unique for each cluster respectively (see: Additional files 1,2). This suggests that biological processes (host responses) could be associated with the spatial expression profiles of their corresponding genes. To study this further we used the affinity propagation clustering algorithm [21] to determine the number of clusters without a specified cluster number preference value. This grouped the $523 \mathrm{DE}$ genes into 36 more tightly resolved spatial expression clusters, comprising 35 clusters with between three and 57 genes and a single cluster containing only one gene (Fig. 5a). 28 of 35 clusters were enriched for biological processes (see: Additional file 3). To test if different spatial expression patterns enrich different biological processes, we correlated all multi-gene clusters based on the presence/absence of all enriched GO-terms. We saw little overlap in biological processes between clusters, indicating that each spatial expression cluster enriched slightly different GO-terms (Fig. 5b and Additional file 3).

\section{Characterisation of spatial regulatory elements}

We characterised the expression patterns of the 36 obtained clusters in Fig. 5. 11 clusters $(1,2,6,8,12,15$, $23,25,28,30,35)$ showed a peak of higher expression at the site of flg22 perception. 14 clusters $(3,5,7,10,11,14$, $18,19,21,22,26,29,32,33)$ indicated spatially elevated gene expression patterns with higher expression also at sites adjacent to the area of flg22 perception. The remaining 11 clusters showed less clear expression profiles (Additional file 2).

To identify plant regulatory elements that are potentially involved in PAMP perception and signal propagation to adjacent areas, we selected DE genes belonging to the flg22 locally and adjacently elevated clusters, and then filtered the genes for the TAIR-10 [22] GO-terms 'receptor' and 'transcription'. This included the leucinerich repeat receptor like kinase (LRR-RLK) RLK7 (cluster 1) which was locally elevated, whereas the LRR-RLK CERK1 and the serine/threonine-protein kinase PSKR1 while strongly elevated at the area of flg22 perception were also broadly expressed throughout all sites (cluster 7). We detected a larger set of $48 \mathrm{DE}$ genes associated with transcriptional processes. WRKY (15 genes), ERF 
(8 genes) and MYB (4 genes) transcription factor family members [23-25] were the most abundant in our dataset.

To start to understand the possible gene regulatory network controlling this spatial expression we used the TF2Network software [26] to search for putative regulatory interactions between these $48 \mathrm{DE}$ genes i.e. by transcription factor binding. The resulting gene networks are built from genes with at least one target and a q-value $<0.01$ (see Additional file 1). These linked 4 transcription factors of which all belonged to the WRKY family (WRKY11, WRKY15, WRKY17 and WRKY47) to 388 other DE genes indicating a possible regulatory network (TF2Network authors suggest their tools has a very low false positive rate, whilst being sensitive enough to detect $75-92 \%$ of correct links).

Of the detected transcription factors WRKY17 (cluster 4) and WRKY47 (cluster 8) were associated with local expression patterns, whereas WRKY11 (cluster 10) and WRKY15 (cluster 10) showed spatially wider expression.

\section{Discussion}

The ability to profile gene expression patterns in small specific areas without bulk sequencing provides access to lower level transcripts, especially tissue and cell specific ones [3-5, 27-29]. Spatial, low RNA-input transcriptomics methods allow deeper insights in how an organism develops and reacts to its environment than conventional "gross-scale" RNA-seq methods [4-6]. By combining rapid dissection with GaST-seq, we were able to reconstruct spatial transcriptional differences across organs and localised defence responses.

Although some specialised protocols are already available to profile transcriptomes from minute input amounts such as single-cells $[2,10]$, or even nuclei [11, 12], these detailed techniques do not retain the spatial information of a starting tissue and any time-consuming experimental procedures to preserve spatial data could induce experimental bias by altering the transcriptome. For spatial analyses in plants LCM $[14,15]$ methods for fine-scale transcriptome analyses are available, however, these procedures are time-consuming and this limits the scale of the application. Large scale spatial analysis have been performed in the past [8], but still required bulk sampling of material by pooling multiple replicates. Methods relying on sample dissection and reaction-tube processing of tissue sections to sequencing libraries have already proven to be able to identify transcripts patterns in the zebrafish embryo [5] allowing to process multiple samples easily for modelling the transcriptome landscape of an entire organism. Recently Giacomello et al. [6] published a workflow to blot the transcriptome landscape from permeabilised plant tissues by vertical diffusion onto a slide containing an array of barcoded primers and on slide library construction which maintained the mRNA's location via the barcode. This method, for the first time in plants, allowed access to spatial transcriptome data in thin tissue slices of plant organs with a great level of resolution. However, gathering and optimisation of permeabilization conditions of thin tissue sections can be challenging especially if the tissue due to the volume and shape of the sample, are not suitable to be processed on an array and the workflow is only commercially accessible.

Plants grow in a microbiologically rich environment with their own microbiomes and even symbionts [30], but they are also attacked by pathogens, pests, herbivores and other biotic stresses [31]. As plants can't move away from attacks they defend themselves using molecular and cellular biology responses, however overstimulation of these processes leads to stunted development and lower fitness [17]. As plants must balance the need to defend themselves against constant plant-microbial interactions and attack [17] we hypothesised that local attacks might be integrated into a plant-wide defence response decision. Yet there are no appropriate assays to measure the molecular and cell biology changes at the required resolution. Here, we demonstrate a novel micro-scale method to pursue spatial transcriptomics experiments in plants in an easy manner based on easily accessible methods in sequencing library construction and bioinformatics tools.

We developed a robust micro-spatial expression methodology that enables the creation of transcriptome level maps from very small amounts of any eukaryotic tissue. The GaST-seq workflow evolved by transferring elements from existing single-cell RNA-seq methods [32, 33] from animal systems to plants and refining these methods for stable, low-cost generation of sequencing libraries from small amounts of RNA starting material. This allows the design of experiments in which spatial information is required but only small pieces of tissue can be obtained.

In the process of method development, we combined 96-well format low-input plant tissue lysis with a Brassicaceae (i.e. Arabidopsis) and crop plant (i.e. wheat and canola) compatible mRNA extraction step [34]. We tested and included several features to efficiently generate double stranded cDNA (ds-cDNA) with reduced PCR amplification in both ds-cDNA synthesis and subsequent amplification after Nextera tagmentation. We introduced sample specific barcodes in the Nextera amplification step to allow pooling of 2304 of samples per sequencing run. This optimisation altogether allowed us to construct sequencing libraries by hand for just $£ 6.00$ per library (see Additional file 2) in comparison to $£ 65.56$ for an Illumina TruSeq library (RS-122-2001, Illumina) or $£$ 
62.60 for a SMARTer PCR cDNA Synthesis Kit library (634926, TaKaRa).

In our benchmarking experiments we compared the GaST-seq workflow with the widely used Illumina TruSeq sequencing protocol and show that the GaST-seq method compares well with this common commercial RNA-seq protocol (see: Additional file 1). We also show that GaST-seq can detect transcript level differences across 1D leaf sections in distinct leaf elements such as leaf margins or vascular tissues and that spatial mapping of transcript levels to specific sections of leaves is possible, which allows drawing of transcriptional expression profiles across tissues. This easily used, low cost protocol makes feasible experiments that require spatial transcriptome analysis.

To apply the GaST-seq method for studying biotic actions we challenged $A$. thaliana leaves with the bacterial peptide flg22, a conserved 22 amino acid sequence of the bacteria flagellin protein, which to the plant indicates an encounter with potentially pathogenic bacteria [35]. Plants recognize such potential threats as the pathogenic cell surface molecules, so called Pathogen-Associated Molecular Patterns (PAMPs), perceived by the plant Pattern Recognition Receptors (PRRs) on the plant cell surface [36]. This event initiates an intracellular plant signalling cascade leading eventually to immunity or disease [17, 37]. In our experiments we could detect the triggering of immune and defence response related biological processes and show that the results obtained by RNA-seq are independently reproducible using qRTPCR (see: Additional file 1). We were able to find overlap in our data with already described flg22 elicited (FLARE) genes from a gross-scale experiment using a strong stimulus [18]. In comparative analyses of our dataset with the spatial expression patterns of the described FLARE genes we were able to identify genes which share similar spatial expression and are potential novel FLARE genes. Cluster based analysis of spatial expression data revealed sets of genes with highly similar expression profiles enriched in distinct biological processes; including FLARE genes to which we add new and increased expression resolution. Characterisation of spatial cluster expression profiles highlighted plant regulatory elements with local or spatially elevated expression levels and so potential short distance signal propagators upon flg22 stimulus.

In a proof of principle experiment applying the oomycte Albugo laibachii NC14 to A. thaliana leaves we also recovered both host and pathogen transcript data, indicating that dual-host pathogen experiments (between eukaryotic organisms) are possible (see: Additional files 1, 2).

\section{Conclusions}

We find that GaST-seq allows reproducible spatial-transcriptome experiments in plant tissues. Proof of concept experiments highlighted the usability of the method in characterising spatial differences within organs, and changes induced by biotic stimuli of bacterial PAMPs. The workflow also compares well to widely used RNAseq protocols such as Illumina TruSeq sequencing but can be conducted at a fraction $(\sim 1 / 10$ th) of the library preparation costs of Illumina TruSeq. Furthermore, as our ds-cDNA synthesis method is based on single-cell technologies [32], even smaller sections could be processed while maintaining efficient library and sequencing results.

\section{Methods}

\section{Plant growth}

For our experiments we used 4-6 week old $A$. thaliana Col-0 plants that were grown in a controlled environment room with an $8 \mathrm{~h}$ light, $16 \mathrm{~h}$ dark cycle at a constant temperature of $22{ }^{\circ} \mathrm{C}$ and $70 \%$ humidity.

\section{Flg22 exposure experiments}

Before flg22 treatment experiments, we transferred the plants from the controlled environment room to a laboratory working bench (room with constant light exposure and temperature). To elicit plant responses with flg22 we either syringe infiltrated [38] the peptide or spotted a droplet of flg22 on a leaf using a pipette.

To produce small, local infiltration spots we used a $1 \mathrm{ml}$ syringe (BS01T, R\&L Slaughter Ltd, Basildon, UK) loaded with $500 \mathrm{nM}$ flg22 peptide solution. By application of mild pressure on the plunger of the syringe when infiltrating we produced an approximately $2-3 \mathrm{~mm}$ diameter infiltration spot on the left-hand side of a leaf. In parallel to flg22 infiltration we produced an infiltration series with DNase/RNase-free water as control. The plants were subsequently incubated on the laboratory working bench for $1 \mathrm{~h}$ until sampling.

For the flg22 spotting experiment we loaded a $1 \mu \mathrm{l}$ droplet of $500 \mathrm{nM}$ flg22 on the abaxial surface of a leaf using a pipette (diameter approximately $1 \mathrm{~mm}$ ). The flg22 was pipetted onto the left half of the leaf and a $1 \mu \mathrm{l}$ droplet of the water control droplet spotted on the right half of the leaf. After spotting the plants were incubated for $1 \mathrm{~h}$ on the laboratory bench before sampling.

\section{A. laibachii exposure experiments}

The experimental description and analysis of the A. laibachii experiment can be found in Additional file 1. 


\section{Leaf sectioning and sample harvesting}

We used single margin razor blades (T586, Agar Scientific Ltd., Stansted, UK) to cut leaves into approximately $1 \mathrm{~mm}^{2}$ small leaf squares. To create a clean surface for cutting we used the pealed, non-sticky paper cover of a 96-well plate seal (AB0580, Thermo Fisher Scientific, Waltham, USA). With a previously in RNaseZAP (AM9780, Thermo Fisher Scientific, Waltham, USA) washed and air-dried forceps (T083, TAAB Laboratories Equipment Ltd, Berks, UK) we transferred each leaf square immediately after cutting into a well of a 96-well plate (E1403-0100-C, Starlab, Milton Keynes, UK) which we had pre-cooled on a 96-well metal block in dry ice $\left(-70{ }^{\circ} \mathrm{C}\right)$, or alternatively, a dry-ice cooled $1.5 \mathrm{ml}$ tube (10051232, Fisher Scientific, Loughborough, UK). The sample wells of 96-well plates were sealed using domed PCR cap strips (AB0602, Thermo Fisher Scientific, Waltham, USA). Post harvesting the samples were stored at $-80{ }^{\circ} \mathrm{C}$ until use.

\section{Leaf sample lysis and preparation for mRNA extraction}

To lyse the leaf samples stored in $1.5 \mathrm{ml}$ tubes we first added $10 \mu \mathrm{l}$ lysis buffer composed of $100 \mathrm{mM}$ Tris$\mathrm{HCl}$ pH 7.5 (BP1757, Fisher Scientific, Loughborough, UK), $500 \mathrm{mM} \mathrm{LiCl} \mathrm{(L7026,} \mathrm{Sigma} \mathrm{Aldrich,} \mathrm{St.} \mathrm{Louis,}$ USA), 10 mM EDTA pH 8.0 (E7889, Sigma Aldrich, St. Louis, USA), 1\% LiDS (L4632, Sigma Aldrich, St. Louis, USA), 5 mM DTT (18064014, Thermo Fisher Scientific, Waltham, USA) to each sample immediately after removing the sample tube from the cold storage.

We subsequently ground the leaf sections in lysis buffer using polypropylene pestles (Z359947, Sigma Aldrich, St. Louis, USA), which, before use, were washed with RNaseZAP (R2020, Sigma Aldrich, St. Louis, USA, three times with $80 \%$ ethanol (32221, Sigma Aldrich, St. Louis, USA) rinsed with UltraPure DNase/RNase-Free Distilled Water (10977049, Thermo Fisher Scientific, Waltham, USA) and air-dried after washing. After sample lysis we transferred the lysate to an ice-cooled 96-well plate and continued with the mRNA extraction.

Samples stored in 96-well plates were lysed by using $1 \mathrm{~mm}$ diameter grade 1000 hardened 1010 carbon steel ball bearings (Simply Bearings Ltd, Leigh, UK). For this, before use of the ball bearings, we treated a bulk batch sequentially with RNaseZAP and DNA AWAY, after this washed the ball bearings three times with $80 \%$ ethanol and transferred them to sterile screw-cap $2.0 \mathrm{ml}$ tubes (E1420-2341, Starlab, Milton Keynes, UK) and heat dried with a slightly loosened lid on a $95{ }^{\circ} \mathrm{C}$ heating block (N2400-4001, Starlab, Milton Keynes, UK).

To lyse the collected leaf samples stored in a 96-well plate, we transferred the 96-well plate to a dry ice temperature cooled 96-well metal block. We carefully opened the domed PCR cap lids to avoid sample spillage and added the 4-6 (room temperature) ball bearings to each sample well. After this we transferred $10 \mu \mathrm{l}$ lysis buffer to each well and re-sealed the plate with new domed PCR cap lids, and immediately proceeded to the 2010 Geno/Grinder (SPEX SamplePrep, Stanmore, UK) disrupting the samples for $30 \mathrm{~s}$ at $1750 \mathrm{rpm}$. We gathered the sampled using a centrifuge (Centrifuge $5910 \mathrm{R}$, Eppendorf UK Ltd, Stevenage, UK) for $10 \mathrm{~s}$ at $2000 \times$ rcf. A strongly green-coloured solution without any remaining solid leaf material indicated good sample lysis. If satisfactory sample lysis was not achieved, we disrupted the samples again for another $10 \mathrm{~s}$ on the 2010 Geno/Grinder at $1750 \mathrm{rpm}$ and centrifuged for $30 \mathrm{~s}$ at $2000 \times$ rcf. We immediately transferred the lysis solutions into a new 96-well plate using a $10 \mu \mathrm{l}$ multichannel pipette. After transfer of the lysis solutions, we stored the new 96-well plate on ice, discarded the 96-well plate containing the ball bearings and proceeded immediately with mRNA extraction. For a laboratory compatible version of the workflow see: Additional file 1.

\section{Leaf $\mathrm{mRNA}$ purification}

The leaf tissue mRNA was purified using $1 \mu \mathrm{l}$ NEBNext Poly(A) mRNA Magnetic Isolation Module oligo-dT(25) beads (E7490, New England Biolabs Ltd, Hitchin, UK) per extraction. Previous to the extraction the required volume of oligo-dT(25) magnetic beads was washed twice in $200 \mu \mathrm{l}$ lysis buffer on a DynaMag-2 Magnet rack (12321D, Thermo Fisher Scientific, Waltham, USA) and resuspended in $10 \mu \mathrm{l}$ lysis buffer for each $1 \mu \mathrm{l}$ oligo$\mathrm{dT}(25)$ beads input volume. The beads were mixed by a quick vortex and $10 \mu \mathrm{l}$ of the resuspended beads were transferred to each well of the 96-well plate containing the lysis solutions. The wells were sealed with domed PCR cap strips, the 96-well plate vortexed briefly and attached to a tube rotator (444-0502, VWR International Ltd, Luterworth, UK) with adhesive tape. After 10 min rotation we collected the lysis solution at the bottom of the wells by spinning the plate for $10 \mathrm{~s}$ at $2000 \times$ rcf and pelleted the oligo-dT(25) magnetic beads on a 96-ring magnetic plate (A001219, Alpaqua, Beverly, USA). Using a multichannel pipette we washed the oligo$\mathrm{dT}(25)$ magnetic beads twice with $50 \mu \mathrm{l}$ Wash Buffer A $(10 \mathrm{mM}$ Tris- $\mathrm{HCl}$ pH7.5, $0.15 \mathrm{M} \mathrm{LiCl}, 1 \mathrm{mM}$ EDTA, $0.1 \%$ LiDS) and once with Wash Buffer B (10 mM Tris$\mathrm{HCl} \mathrm{pH} \mathrm{7.5,} \mathrm{0.15} \mathrm{M} \mathrm{LiCl,} 1$ mM EDTA). After washing we centrifuged the plate for $10 \mathrm{~s}$ at $2000 \mathrm{x}$ rcf to collect the remaining Wash Buffer $B$ at the bottom of the tube, pelleted the oligo-dT(25) magnetic beads on a magnet and removed the remaining volume of Wash Buffer B with a multichannel pipette. The oligo-dT(25) beads were resuspended immediately in $8 \mu \mathrm{l}$ DNase/RNase-Free water, 
incubated for $2 \mathrm{~min}$ at $80{ }^{\circ} \mathrm{C}$ on a G-Storm GS1 thermal cycler (G-Storm, Somerton, UK), then immediately pelleted on a 96-ring magnetic plate to elute the mRNA off and separate from the oligo-dT(25) beads. The solutions containing the purified mRNA were immediately transferred to a new 96-well plate, which was placed in a $-80{ }^{\circ} \mathrm{C}$ freezer until needed. For a laboratory compatible version of the workflow see: Additional file 1.

\section{Double-stranded cDNA synthesis reaction}

For ds-cDNA synthesis we used a protocol based on the template switching mechanism of the reverse transcriptase enzymes [39]. Briefly: $2.50 \mu \mathrm{l}$ extracted mRNA was mixed with $2 \mu \mathrm{l} 5 \times$ First Strand buffer (18064014, Thermo Fisher Scientific, Waltham, USA), $1 \mu \mathrm{l} 10 \mathrm{mM}$ dNTPs (10297018, Thermo Fisher Scientific, Waltham, USA), $1 \mu$ 5'-biotinylated $10 \mu \mathrm{M}$ STRT-V3-T30-VN oligonucleotide: $\quad 5^{\prime}$-/5Biosg/TTAAGCAGTGGTATCAAC GCAGAGTCGACTTTTTTTTTTTTTTTTTTTTTT TTTTTTTVN-3' (Integrated DNA Technologies, Leuven, BE), $1 \mu \mathrm{l} 20 \mathrm{mM}$ DTT (18064014, Thermo Fisher Scientific, Waltham, USA), $0.10 \mu \mathrm{l} 40 \mathrm{U} / \mu \mathrm{l}$ RNase Inhibitor (M0314S, New England Biolabs Ltd, Hitchin, UK), $0.25 \mu \mathrm{l} 10 \mu \mathrm{M}$ template switching oligo 5'-AAGCAG TGG TAT CAA CGC A GA GT G CAG UGC UTG ATG ATGGrGrGrG-3' (Integrated DNA Technologies, Leuven, BE), $0.30 \mu \mathrm{l} 200 \mathrm{U} / \mu \mathrm{l}$ SuperScript II Reverse Transcriptase (18064014, Thermo Fisher Scientific, Waltham, USA), $0.30 \mu \mathrm{l} 100 \mu \mathrm{M} \mathrm{MnCl}$ (M1787, Sigma Aldrich, St. Louis, USA) and $1.55 \mu \mathrm{l}$ DNase/RNase-Free water to a total reaction volume of $10 \mu \mathrm{l}$. The reverse transcription reaction was run in a G-Storm GS1 thermal cycler for $90 \mathrm{~min}$ at $42{ }^{\circ} \mathrm{C}$ with additional $10 \mathrm{~min}$ at $72{ }^{\circ} \mathrm{C}$ to inactivate the reverse transcriptase. After reverse transcription we immediately added $2 \mu \mathrm{l}$ RNase H (M0297S, New England Biolabs Ltd, Hitchin, UK) diluted to 0.5 U/ $\mu \mathrm{l}(5 \mathrm{U} / \mu \mathrm{l}$ stock concentration) to the reaction and incubated the reaction in the GS1 thermal cycler for $30 \mathrm{~min}$ at $37^{\circ} \mathrm{C}$. The RNase $\mathrm{H}$ treated reactions were purified using a $0.83 \times(10 \mu \mathrm{l})$ AMPure XP bead ratio (Beckman Coulter, High Wycombe, UK) and eluted in $18 \mu \mathrm{l} 1 \times \mathrm{TE}$ buffer. After this step we added $5 \mu \mathrm{l} 5 \times$ Kapa HiFi PCR buffer (KK2102, KAPA BioSystems, Wilmington, USA), $0.75 \mu \mathrm{l}$ $10 \mathrm{mM}$ dNTPs, $0.75 \mu \mathrm{l} 10 \mu \mathrm{M}$ PCR+G primer $5^{\prime}$-GAA GCAGTGGTATCAACGCAGAGT-3' (Integrated DNA Technologies, Leuven, BE) and $0.50 \mu \mathrm{l} 1 \mathrm{U} / \mu \mathrm{l}$ Kapa HiFi polymerase (KK2102, KAPA BioSystems, Wilmington, USA) to the cleaned ds-cDNA resulting in a total reaction volume of $25 \mu \mathrm{l}$ and amplified the ds-cDNA in a G-Storm GS1 thermal cycler according to the following programme: (1) $3 \mathrm{~min}$ at $94{ }^{\circ} \mathrm{C}$, (2) 17 cycles with $30 \mathrm{~s}$ at $94{ }^{\circ} \mathrm{C}, 30 \mathrm{~s}$ at $63{ }^{\circ} \mathrm{C}$ and $1 \mathrm{~min} 30 \mathrm{~s}$ at $72{ }^{\circ} \mathrm{C}$, (3) a final elongation step for $5 \mathrm{~min}$ at $72{ }^{\circ} \mathrm{C}$. The amplified libraries were purified using a $1 \times(25 \mu \mathrm{l})$ AMPure XP bead ratio and eluted in $20 \mu \mathrm{l} 1 \times \mathrm{TE}$ buffer. The ds-cDNA libraries could be stored at this point in a $-20{ }^{\circ} \mathrm{C}$ freezer. Before continuing with Illumina sequencing library preparation, we measured the ds-cDNA library concentrations with the Qubit 2.0 Fluorometer (Thermo Fisher Scientific, Waltham, USA) dsDNA HS Assay Kit reagents (Q32854, Thermo Fisher Scientific, Waltham, USA) and also assessed the size distributions of randomly picked libraries on an Agilent Bioanalyser (G2939BA, Agilent Technologies, Stockport, UK) using the Agilent High Sensitivity DNA Kit (5067-4626, Agilent Technologies, Stockport, UK).

At later stages we modified the ds-cDNA synthesis integrating elements of the Smart-seq2 protocol [40]. The reverse transcription reactions of GaST-seq-1.0 (as described above) and Smart-seq2 were already highly similar, but Smart-seq2 had proven to require less handson time than the GaST-seq-1.0 reverse transcription workflow. GaST-seq-1.1 uses the Smart-seq2 ds-cDNA synthesis with minor modifications, briefly: $2.50 \mu \mathrm{l}$ extracted mRNA were combined with $1 \mu \mathrm{l} 10 \mu \mathrm{M}$ Smartseq2 Oligo-dT30VN (5'-AAGCAGTGGTATCAACGC AGAGTACTTTTTTTTTTTTTTTTTTTTTTTTTT TTTTVN-3', Integrated DNA Technologies, Leuven, $\mathrm{BE})$ and $1 \mu \mathrm{l} 10 \mathrm{mM}$ dNTPS to a total volume of $4.5 \mu \mathrm{l}$. To anneal the Smart-seq2 Oligo-dT30VN we incubated the library for $30 \mathrm{~s}$ at $72{ }^{\circ} \mathrm{C}$ and snap-cooled the mixture on ice. The reverse transcription was conducted by adding the following reagents to the reaction with a final reaction volume of $10 \mu \mathrm{l}: 2 \mu \mathrm{l} 5 \times$ First Strand buffer, $2 \mu \mathrm{l} 5 \mathrm{M}$ betaine (B0300, Sigma Aldrich, St. Louis, USA), $0.06 \mu 11 \mathrm{M} \mathrm{MgCl}_{2}$ (AM9530G, Thermo Fisher Scientific, Waltham, USA), $0.5 \mu \mathrm{l} 100 \mathrm{mM}$ DTT, $0.25 \mu \mathrm{l} 40 \mathrm{U} /$ $\mu$ RNase Inhibitor (2313A, Takara Clontech, Mountain View, USA), $0.10 \mu \mathrm{l} 10 \mu \mathrm{M}$ Smart-seq2 template switching oligo (5'-AAGCAGTGGTATCAACGCAGAGTA CATrGrG+G-3', Exiqon, Vedbaek, DK), $0.50 \mu \mathrm{l} 200 \mathrm{U} / \mu \mathrm{l}$ SuperScript II Reverse Transcriptase, and $0.09 \mu$ DNase/ RNase-free water. We performed the reverse transcription reaction for (1) $90 \mathrm{~min}$ at $42{ }^{\circ} \mathrm{C}$, (2) 15 cycles with $2 \mathrm{~min}$ at $50{ }^{\circ} \mathrm{C}$ and $2 \mathrm{~min}$ at $42{ }^{\circ} \mathrm{C}$ and finally (3) $15 \mathrm{~min}$ at $70{ }^{\circ} \mathrm{C}$. After reverse transcription we added $12.50 \mu \mathrm{l}$ $2 \times$ Kapa HiFi HotStart ReadyMix (KK2601, KAPA BioSystems, Wilmington, USA), $0.25 \mu \mathrm{l} 10 \mu \mathrm{M}$ Smart-seq2 IS-PCR primers (5'-AAGCAGTGGTATCAACGC AGAGT-3', Integrated DNA Technologies, Leuven, BE) and $2.25 \mu \mathrm{l}$ DNase/RNase-Free water to the reaction resulting in a total volume of $15 \mu \mathrm{l}$ per reaction. Amplification was performed in a G-Storm GS1 cycler according to the programme: (1) $3 \mathrm{~min}$ at $98{ }^{\circ} \mathrm{C}$, (2) 15 cycles with $20 \mathrm{~s}$ at $98^{\circ} \mathrm{C}, 15 \mathrm{~s}$ at $67{ }^{\circ} \mathrm{C}$ and $6 \mathrm{~min}$ at $72{ }^{\circ} \mathrm{C}$ and a (3) final elongation step for $5 \mathrm{~min}$ at $72{ }^{\circ} \mathrm{C}$. The PCR 
reactions were purified using a $0.65 \times(9.75 \mu \mathrm{l})$ AMPure $\mathrm{XP}$ cleanup and eluted in $20 \mu \mathrm{l} 1 \times \mathrm{TE}$ buffer. After cleanup we measured the ds-cDNA library concentrations with the Qubit 2.0 Fluorometer dsDNA HS Assay Kit reagents and loaded randomly selected libraries on the Agilent Bioanalyser using the Agilent High Sensitivity DNA Kit before continuing with Illumina sequencing library prepration. For a laboratory compatible version of the workflow see: Additional file 1.

\section{Illumina library preparation from ds-cDNA}

We prepared Illumina sequencing libraries using an Illumina Nextera (FC-121-1030, Illumina Cambridge, UK) based protocol with minor modifications: we exclusively used the Tagment DNA Enzyme 1 and the Tagment DNA Buffer and amplified the tagmented DNA with the Kapa 2G Robust Polymerase (KK5024, Sigma Aldrich, St. Louis, USA). We used custom Nextera barcodes that allow us to multiplex hundreds of samples (see: Additional file 2) [41].

We reduced the costs of the library preparation by reducing the total tagmentation reaction volume to $5 \mu \mathrm{l}$ (from $50 \mu \mathrm{l}$ as recommended) with $1 \mathrm{ng}$ ds-cDNA library input and using less enzyme. We performed a titration experiment of Tagment DNA Enyzme vs. $1 \mathrm{ng}$ of selected ds-cDNA libraries aiming for Illumina sequencing libraries with a modal insert size distribution in the range of 400-500 bp with little short insert fragments and found that $0.1 \mu$ l Nextera enzyme was optimal.

The Nextera reactions were performed by combining $1 \mathrm{ng}$ of ds-cDNA (air-dried over-night at room temperature in a drawer with the 96-well plate loosely covered to allow evaporation of liquid) with $2.5 \mu \mathrm{l} 2 \mathrm{x}$ Nextera buffer, $2.4 \mu \mathrm{l}$ water and $0.1 \mu \mathrm{l}$ Nextera enzyme on ice. The tagmentation plate was immediately transferred for $5 \mathrm{~min}$ at $55{ }^{\circ} \mathrm{C}$ on a G-Storm GS1 thermal cycler. Meanwhile we prepared a fresh 96-well plate with $2.0 \mu \mathrm{l} 2.5 \mu \mathrm{M}$ P5 and $2.0 \mu \mathrm{l} 2.5 \mu \mathrm{M}$ P7 custom multiplexing primers (see: Additional file 2). After tagmentation we transferred the tagmentation reactions to the previously prepared 96-well plate containing the sequencing adapters (see above) and added the following to each well: $5.00 \mu \mathrm{l} 5 \times$ Kapa $2 \mathrm{G}$ Robust Buffer, $0.50 \mu \mathrm{l} 10 \mathrm{mM}$ dNTPs, $0.10 \mu \mathrm{l} 5 \mathrm{U} / \mu \mathrm{l} \mathrm{Kapa}$ 2G Robust Polymerase, $10.4 \mu \mathrm{l}$ water to a total final volume of $25 \mu \mathrm{l}$.

Amplification was performed on a GStorm GS-1 cycler using the following program: (1) $3 \mathrm{~min}$ at $72{ }^{\circ} \mathrm{C}, 1 \mathrm{~min}$ at $95{ }^{\circ} \mathrm{C}(2) 11$ cycles of $10 \mathrm{~s}$ at $95{ }^{\circ} \mathrm{C}, 30 \mathrm{~s}$ at $65{ }^{\circ} \mathrm{C}, 2 \mathrm{~min}$ $30 \mathrm{~s}$ at $72{ }^{\circ} \mathrm{C}(2)$ a final elongation step for $2 \mathrm{~min} 30 \mathrm{~s}$ at $72{ }^{\circ} \mathrm{C}$. After amplification we purified the libraries using a $0.64 \times$ ratio $(16 \mu \mathrm{l})$ AMPure XP beads, measured the library yields with the Qubit 2.0 Fluorometer dsDNA HS Assay Kit reagents and assessed the size distributions of randomly selected libraries on the Agilent Bioanalyser with the Agilent High Sensitivity DNA Kit. For a laboratory compatible version of the workflow see: Additional file 1.

\section{Sample pooling and sequencing}

For sequencing all library concentrations were determined using Qubit 2.0 Fluorometer using the dsDHA HS Assay kit reagents and pooled at equal molarity. The profile and concentration of the final library pool was assessed on the Agilent Bioanalyser using Agilent High Sensitivity DNA Kit Sequencing reagents. After this the pooled samples were shipped to the Earlham Institute for sequencing. Quality control and data demultiplexing was performed by the Earlham Institute Genomics Pipelines facilities. Samples were sequenced using Illumina HiSeq2500 50 base single-end rapid run sequencing for the A. thaliana wounding and A. thaliana flg22 infiltration datasets Illumina NextSeq 50075 base single-end for the A. thaliana untreated leaf dataset and Illumina HiSeq 4000150 base paired-end sequencing for the $A$. thaliana flg22 droplet spotting experiment.

\section{Data quality control and mapping}

The sequencing reads were quality controlled using FastQC-0.11.5 [42]. After quality control we used cutadapt-1.17 [43] to trim low-quality bases (-q20) and remove Oligo-dT, template switching oligos, primer and Illumina Nextera library preparation sequences $(-\mathrm{n} 5$ -e 0.05 -overlap 10). We also removed sequences with less than 40 bases (-minimum-length 40 ) and sequences containing N's $(-\max -n)$ from the dataset with cutadapt-1.17. After adapter and quality trimming we reassessed the reads a second time with FastQC-0.11.5. We mapped the reads to the $A$. thaliana TAIR10 release 37 genome assembly using STAR-2.5.1b [44] default settings and assessed mapping scores, duplication levels, GC-bias and gene-body coverage after mapping with RSeQC-2.6.4 [45]. Reads were counted with HTSeq-count-0.6.0 [46] default settings.

\section{Differential-expression analysis and GO-term enrichment}

Differential expression analysis was performed using DESEq2-1.20.0 [47] in the statistical language R-3.5.1 using the workflow described by Love et al. [48] but by pre-filtering the dataset for rows with less than 10 rather than 1 raw read counts. DE-genes were called with a q-value threshold $<0.05 \%$.

Across leaf DE-gene expression plots were prepared using R-3.5.1; in brief: We imported all samples with DESeq2-1.20.0 and calculated a table with normalised expression values as in the workflow described by Love et al. [48]. Next, we calculated the average expression 
value of each gene in each leaf square across all biological replicates. As a final step we normalised the expression values of the leaf squares. For this we divided the mean expression value of each leaf square of a gene with the mean expression value across all leaf squares of the same gene. The $\log 2$ transformed plots of the so normalised data were generated using ggplot2-3.1.0 [49].

Affinity propagation clustering of the normalised expression tables was performed using the R-3.5.1 library apcluster-1.4.7 and a Pearson distance matrix of the normalised data for apclustK and apclust [21] default settings. The number of clusters was either empirically determined by continuously increasing the preferred cluster number in the apclustK function and visualising the expression profiles of the clusters using ggplot2-3.1.0 or determined without providing a cluster number preference value using the apclust function.

GO-term enrichment analysis on DE-genes was performed using the R-3.5.1 Bioconductor library ClusterProfiler-3.8.1 [50] with the settings (Statistical test: Hypergeometric test, Multiple testing correction: Benjamini and Hochberg False Discovery Rate correction, False Discovery Rate cutoff: 0.01) and the Bioconductor library org.At.tair.db-3.6.0 as organism database [51].

\section{Supplementary information}

Supplementary information accompanies this paper at https://doi. org/10.1186/s13007-019-0498-5.

Additional file 1. Comparison of GaST-seq with Illumina TruSeq, qRT-PCR validation of DE gene expression, wounding time-series $\mathrm{GO}$ enrichment, Albugo laibachii spatial transcriptomics experiment, all wet-lab protocols of the GaST-seq workflow.

Additional file 2. Read numbers, ENA accessions, DE genes, GO accessions, clustering information, FLARE associations of experiments.

Additional file 3. GO-term enrichments of spatial affinity propagation clustering.

\section{Acknowledgements}

We thank David Prince for providing the A. laibachii NC14.

\section{Authors' contributions}

MG, WV and DH established protocols. MG, WV and AL prepared sequencing libraries. MG analysed the data. IM advised on protocols and data analysis. MG and MDC wrote the manuscript. WV, MG and MDC designed the study. All authors read and approved the final manuscript.

\section{Funding}

This work was strategically funded by the Biotechnology and Biological Sciences Research Council (BBSRC), Institute Strategic Programme Grant (BB/ J004669/1) at the Earlham Institute (formerly The Genome Analysis Centre, Norwich), a BBSRC National Capability Grant (BB/J010375/1), a BBSRC Core Strategic Programme Grant (BB/CSP17270/1), a BBSRC DTP Studentship Award (BB/M011216/1) and by the Natural History Museum.

\section{Availability of data and materials}

Sequencing reads for the GaST-seq vs. TruSeq comparison are available under the ENA study Accession Number PRJEB31337. Sequencing reads for the wounding experiment are available under the ENA study Accession Number
PRJEB31311. Sequencing reads for the untreated leaf spatial transcriptomics experiment are available under the ENA study Accession Number PRJEB31314. Sequencing reads for the flg22/water infiltration experiment are available under the ENA study Accession Number PRJEB31312. Sequencing reads for the flg22/water droplet spotting experiment are available under the ENA study Accession Number PRJEB31313. Sequencing reads for the Albugo laibachii $\times$ Arabidopsis.thaliana spatial transcriptomics experiment are available under the ENA study Accession Number PRJEB31803.

Ethics approval and consent to participate Not applicable.

\section{Consent for publication}

This study abides by UK guidelines and legislation for plant science research.

\section{Competing interests}

The authors declare that they have no competing interests.

\section{Author details}

${ }^{1}$ John Innes Centre, Norwich Research Park, Norwich, UK. ${ }^{2}$ Earlham Institute, Norwich Research Park, Norwich, UK. ${ }^{3}$ Enza Zaden, Enkhuizen, NL, Netherlands. ${ }^{4}$ Natural History Museum, London, UK.

Received: 31 July 2019 Accepted: 27 September 2019

Published online: 10 October 2019

\section{References}

1. Müller B, Grossniklaus U. Model organisms-a historical perspective. J Proteomics. 2010;73:2054-63.

2. Mincarelli L, Lister A, Lipscombe J, Macaulay IC. Defining cell identity with single-cell omics. Proteomics. 2018;18:1700312.

3. Crosetto N, Bienko M, van Oudenaarden A. Spatially resolved transcriptomics and beyond. Nat Rev Genet. 2015;16:57-66.

4. Stahl PL, Salmen F, Vickovic S, Lundmark A, Navarro JF, Magnusson J, et al. Visualization and analysis of gene expression in tissue sections by spatial transcriptomics. Science. 2016;353:78-82.

5. Junker JP, Noël ES, Guryev V, Peterson KA, Shah G, Huisken J, et al. Genome-wide RNA tomography in the Zebrafish Embryo. Cell. 2014;159:662-75.

6. Giacomello S, Salmén F, Terebieniec BK, Vickovic S, Navarro JF, Alexeyenko $A$, et al. Spatially resolved transcriptome profiling in model plant species. Nat Plants. 2017;3:17061.

7. Genomics Rusk N. Spatial transcriptomics. Nat Methods. 2016;13:710-1.

8. Mulema JMK, Denby KJ. Spatial and temporal transcriptomic analysis of the Arabidopsis thaliana-Botrytis cinerea interaction. Mol Biol Rep. 2012:39:4039-49.

9. Ghawana S, Paul A, Kumar H, Kumar A, Singh H, Bhardwaj PK, et al. An RNA isolation system for plant tissues rich in secondary metabolites. BMC Res Notes. 2011;4:85

10. Borges F, Gardner R, Lopes T, Calarco JP, Boavida LC, Slotkin R, et al. FACSbased purification of Arabidopsis microspores, sperm cells and vegetative nuclei. Plant Methods. 2012;8:44.

11. Deal RB, HenikoffS. The INTACT method for cell type-specific gene expression and chromatin profiling in Arabidopsis thaliana. Nat Protoc. 2010;6:56.

12. Gaiero P, Šimková H, Vrána J, Santiñaque FF, López-Carro B, Folle GA, et al. Intact DNA purified from flow-sorted nuclei unlocks the potential of next-generation genome mapping and assembly in Solanum species. MethodsX. 2018;5:328-36.

13. Duncan S, Olsson T, Hartley M, Dean C, Rosa S. Single molecule RNA FISH in Arabidopsis root cells. BIO-Protoc. 2017;7. https://bio-protocol.org/ e2240. Accessed 5 July 2018.

14. Kerk NM. Laser capture microdissection of cells from plant tissues. Plant Physiol. 2003;132:27-35.

15. Chan AC, Khan D, Girard IJ, Becker MG, Millar JL, Sytnik D, et al. Tissuespecific laser microdissection of the Brassica napus funiculus improves gene discovery and spatial identification of biological processes. J Exp Bot. 2016;67:3561-71 
16. Martin LBB, Nicolas P, Matas AJ, Shinozaki Y, Catalá C, Rose JKC. Laser microdissection of tomato fruit cell and tissue types for transcriptome profiling. Nat Protoc. 2016;11:2376-88.

17. Jones JDG, Dangl JL. The plant immune system. Nature. 2006;444:323-9.

18. Navarro $L$. The Transcriptional Innate Immune Response to flg 22 Interplay and overlap with Avr gene-dependent defense responses and bacterial pathogenesis. Plant Physiol. 2004;135:1113-28.

19. Farmer E, Farmer E, Mousavi S, Lenglet A. Leaf numbering for experiments on long distance signalling in Arabidopsis. Protoc Exch. 2013. http:// www.nature.com/protocolexchange/protocols/2787. Accessed 3 Nov 2016.

20. Supek F, Bošnjak M, Škunca N, Šmuc T. REVIGO Summarizes and visualizes long lists of gene ontology terms. PLoS ONE. 2011;6:e21800.

21. Frey BJ, Dueck D. Clustering by passing messages between data points. Science. 2007;315:972-6.

22. Berardini TZ, Reiser L, Li D, Mezheritsky Y, Muller R, Strait E, et al. The arabidopsis information resource: Making and mining the "gold standard" annotated reference plant genome: Tair: Making and Mining the "Gold Standard" Plant Genome. Genesis. 2015;53:474-85.

23. Pandey SP, Somssich IE. The role of WRKY transcription factors in plant immunity. Plant Physiol. 2009;150:1648-55.

24. Xie Z, Nolan TM, Jiang H, Yin Y. AP2/ERF transcription factor regulatory networks in hormone and abiotic stress responses in Arabidopsis. Front Plant Sci. 2019;10:228.

25. Dubos C, Stracke R, Grotewold E, Weisshaar B, Martin C, Lepiniec L. MYB transcription factors in Arabidopsis. Trends Plant Sci. 2010;15:573-81.

26. Kulkarni SR, Vaneechoutte D, Van de Velde J, Vandepoele K. TF2Network: predicting transcription factor regulators and gene regulatory networks in Arabidopsis using publicly available binding site information. Nucleic Acids Res. 2018;46:e31.

27. Ryu KH, Huang L, Kang HM, Schiefelbein J. Single-cell RNA sequencing resolves molecular relationships among individual plant cells. Plant Physiol. 2019;179:1444-56.

28. Denyer T, Ma X, Klesen S, Scacchi E, Nieselt K, Timmermans MCP. Spatiotemporal developmental trajectories in the Arabidopsis root revealed using high-throughput single-cell RNA sequencing. Dev Cell. 2019;48(840-852):e5.

29. Jean-Baptiste K, MCFaline-Figueroa JL, Alexandre CM, Dorrity MW, Saunders $L, B u b b K L$, et al. Dynamics of gene expression in single root cells of A. thaliana. Plant Cell. 2019;31:933-1011.

30. Karasov TL, Almario J, Friedemann C, Ding W, Giolai M, Heavens D, et al. Arabidopsis thaliana and Pseudomonas pathogens exhibit stable associations over evolutionary timescales. Cell Host Microbe. 2018;24(168-179):e4.

31. Dangl $J$, Horvath DM, Staskawicz BJ. Pivoting the plant immune system from dissection to deployment. Science. 2013;341:746-51.

32. Picelli S, Faridani OR, Björklund ÅK, Winberg G, Sagasser S, Sandberg R. Full-length RNA-seq from single cells using Smart-seq2. Nat Protoc. 2014;9:171-81.

33. Macaulay IC, Haerty W, Kumar P, Li YI, Hu TX, Teng MJ, et al. G\&T-seq: parallel sequencing of single-cell genomes and transcriptomes. Nat Methods. 2015;12:519-22.
34. Jost $\mathrm{R}$, Berkowitz $\mathrm{O}$, Masle J. Magnetic quantitative reverse transcription PCR: a high-throughput method for mRNA extraction and quantitative reverse transcription PCR. Biotechniques. 2007:43:206-11.

35. Denoux C, Galletti R, Mammarella N, Gopalan S, Werck D, De Lorenzo G, et al. Activation of defense response pathways by OGs and Flg22 elicitors in Arabidopsis seedlings. Mol Plant. 2008;1:423-45.

36. Zipfel C. Pattern-recognition receptors in plant innate immunity. Curr Opin Immunol. 2008;20:10-6.

37. Bent A. Resistance from relatives. Nat Biotechnol. 2016:34:620-1.

38. Underwood W, Somerville SC. Perception of conserved pathogen elicitors at the plasma membrane leads to relocalization of the Arabidopsis PEN3 transporter. Proc Natl Acad Sci. 2013;110:12492-7.

39. Zhu YY, Machleder EM, Chenchik A, Li R, Siebert PD. Reverse transcriptase template switching: a SMART approach for full-length cDNA library construction. Biotechniques. 2001;30:892-7.

40. Picelli S, Björklund \AAsa K., Faridani OR, Sagasser S, Winberg G, Sandberg R. Smart-seq2 for sensitive full-length transcriptome profiling in single cells. Nat Methods. 2013. http://www.nature.com/nmeth/journal/vaop/ ncurrent/full/nmeth.2639.html. Accessed 6 Jan 2015

41. Beier S, Himmelbach A, Colmsee C, Zhang X-Q, Barrero RA, Zhang Q, et al. Construction of a map-based reference genome sequence for barley, Hordeum vulgare L. Sci Data. 2017;4:170044.

42. FastQC: a quality control tool for high throughput sequence data. 2010. http://www.bioinformatics.babraham.ac.uk/projects/fastqc. Accessed 31 Jan 2017.

43. Martin M. Cutadapt removes adapter sequences from high-throughput sequencing reads. EMBnet J. 2011;17:10.

44. Dobin A, Gingeras TR. Mapping RNA-seq reads with STAR: mapping RNAseq reads with STAR. In: Bateman A, Pearson WR, Stein LD, Stormo GD Yates JR, editors. Curr Protoc Bioinforma. Hoboken: Wiley; 2015. https:// doi.org/10.1002/0471250953.bi1114s51.

45. Wang L, Wang S, Li W. RSeQC: quality control of RNA-seq experiments. Bioinforma Oxf Engl. 2012;28:2184-5.

46. Anders S, Pyl PT, Huber W. HTSeq-a Python framework to work with highthroughput sequencing data. Bioinformatics. 2015;31:166-9.

47. Love Ml, Huber W, Anders S. Moderated estimation of fold change and dispersion for RNA-seq data with DESeq2. Genome Biol. 2014;1:15. https //doi.org/10.1186/s13059-014-0550-8.

48. Love MI, Anders S, Kim V, Huber W. RNA-Seq workflow: gene-level exploratory analysis and differential expression. F1000 Res. 2016:4:1070.

49. Wickham H. Ggplot2: elegant graphics for data analysis. New York: Springer; 2009

50. Yu G, Wang L-G, Han Y, He Q-Y. clusterProfiler: an R package for comparing biological themes among gene clusters. OMICS J Integr Biol. 2012;16:284-7.

51. Carlson M. org.At.tair.db: Genome wide annotation for Arabidopsis. 2018.

\section{Publisher's Note}

Springer Nature remains neutral with regard to jurisdictional claims in published maps and institutional affiliations.

\footnotetext{
Ready to submit your research? Choose BMC and benefit from:

- fast, convenient online submission

- thorough peer review by experienced researchers in your field

- rapid publication on acceptance

- support for research data, including large and complex data types

- gold Open Access which fosters wider collaboration and increased citations

- maximum visibility for your research: over 100M website views per year
}

At BMC, research is always in progress.

Learn more biomedcentral.com/submissions 